\title{
Evidence of Martensitic Transformation in Fe-Mn-Al Steel Similar to Maraging Steel
}

\author{
GURUMAYUM ROBERT KENEDY, YI-JYUN LIN, and WEI-CHUN CHENG
}

The Fe-Mn-Al steels claim a low density, and some fall into the category of transformation-induced plasticity (TRIP) steel. In Fe-Mn-Al TRIP steel development, phase transformations play an important role. Herein, the martensitic transformation of an Fe-16.7 Mn-3.4 Al ternary alloy (wt pct) was experimentally discovered, whose equilibrium phases are a single phase of austenite at $1373 \mathrm{~K}$ and dual phases of ferrite and austenite at low temperature. Ferritic lath martensite forms in the prior austenite grains after cooling from $1373 \mathrm{~K}$ under various cooling rates via quenching, air cooling, and furnace cooling. The formation mechanism of the ferritic lath martensite is different from that of traditional ferritic lath martensite in steel and quite similar to that in maraging steel. A slight strain energy coupled with a small temperature gradient can lead to the formation of ferritic lath martensite in the Fe-Mn-Al alloy after cooling from high temperature. It is also found that micro-twins exist in the ferritic lath martensite.

https://doi.org/10.1007/s11661-020-06054-y

(C) The Author(s) 2020

\section{INTRODUCTION}

FE-MN-AL alloys exhibit a low density and some fall into the category of transformation-induced plasticity (TRIP) steels, while Fe-Mn-Al alloys that contain high concentrations of aluminum and manganese have the superior properties of low cost and low density. In addition, knowledge of the Fe-Mn-Al steel phase transformations is essential for future optimal alloy development and processing. Austenite and ferrite are two phases that are common in ferrous alloys, where austenite has a face-centered cubic (FCC) crystal structure and ferrite has a body-centered cubic (BCC) crystal structure. It is generally accepted that, in iron-based alloys, aluminum and manganese play a role as ferrite and austenite stabilizers, respectively, during phase transformations. Specifically, a higher manganese content in the alloy produces a higher proportion of austenite, unlike the $\mathrm{Fe}$ alloys at low temperature that are primarily ferrite. ${ }^{[1-4]}$ Furthermore, in $\mathrm{Fe}-\mathrm{Mn}-\mathrm{Al}$ alloys possessing a low concentration of aluminum and a high concentration of manganese, a fully austenitic microstructure can be preserved even at low temperature. In this condition, the high-temperature

GURUMAYUM ROBERT KENEDY, YI-JYUN LIN and WEICHUN CHENG are with the Department of Mechanical Engineering, National Taiwan University of Science and Technology, 43 Keelung Road, Section 4, Taipei 106, Taiwan. Contact e-mails: D10303804@ mail.ntust.edu.tw; weicheng@mail.ntust.edu.tw

Manuscript submitted March 19, 2020; accepted October 5, 2020.

Article published online October 26, 2020
$\mathrm{BCC}($ i.e., $\delta$ ) to $\mathrm{FCC}($ i.e., $\gamma$ ) phase transformation shifts to a lower temperature. This is unlike common ferrous alloys where this phase transformation is masked by the formation of another BCC $(\alpha)$ phase. By alloying ferrous alloys suitably, therefore, it is possible for the $\delta$ (or $\alpha$ ) to austenite transformation to occur at low temperature. The ferrite-austenite phase transformations in Fe-Mn-Al alloys after cooling from high temperature has been studied for several years. Austenite in the forms of grains, Widmanstätten side-plates, ${ }^{[5]}$ massive grains, ${ }^{[6,7]}$ and $18 \mathrm{R}$ type martensitic needles ${ }^{[8-10]}$ can also be seen in the supersaturated ferrite matrix of the $\mathrm{Fe}-\mathrm{Mn}-\mathrm{Al}$ alloys under various cooling conditions. In Fe-Mn-Al alloys with high $\mathrm{Al}$ and low Mn concentrations, ferrite may exist as the only solid-state phase at low temperature. However, in the single-phase region of $\mathrm{Fe}-\mathrm{Mn}-\mathrm{Al}$ alloys, ferrite is brittle and most likely to be cracked during high-temperature quenching. The ferrite phase has little resistance to plastic deformation and cannot withstand significant thermal contraction upon quenching. ${ }^{[11]}$ Ferrite micro-twins also appear in the single ferrite matrix of $\mathrm{Fe}-\mathrm{Mn}-\mathrm{Al}$ alloys after quenching from high temperature. ${ }^{[12]}$ The twin planes of the BCC ferrite are (112) and the glide directions are $[11 \overline{1}]$. The orientation relationship between the ferrite twin $(t)$ and ferrite matrix $(\alpha)$ is given as follows: $[0 \overline{1} 1]_{t} \|_{[}[\overline{1} 01]_{\alpha}$ and $(121)_{t} \|(211)_{\alpha}$. When BCC twins are studied by TEM, extra reflections from double diffraction appear between the (112) reflections on the diffraction patterns. ${ }^{[13,14]}$

In ferrous alloys, austenite is the high-temperature phase and ferrite is the low-temperature phase. Upon cooling ferrous alloys from high temperature, the phase transformation from austenite-ferrite causes the ferrite 
to form into normal grains, massive grains, Widmanstätten side-plates, and martensitic sub-grains in the supersaturated austenite matrix. Ferritic martensite appears in steel after quenching from high temperature, where ferritic lath martensite forms in low-carbon steel and plate martensite in high-carbon steel. The formation of the ferritic lath martensite is assisted by the movement of the dislocations, while the plate martensite formation is assisted by the development of micro-twins. It is difficult to form martensite in steel with an extremely low carbon content, though ferritic lath martensite forms in nickel-containing maraging steel with a low carbon content. Furthermore, ferritic lath martensite can form in maraging steel after cooling from high temperature even with a low cooling rate. ${ }^{[15-21]}$

No austenite-ferrite martensitic transformation has been studied in the ternary Fe-Mn-Al alloys, either in iron-rich Fe-Al alloys or in those with a high $\mathrm{Mn}$ content. Furthermore, only the austenite- $-\varepsilon$-martensite transformation has been previously discovered in the Fe-Mn alloys, ${ }^{[21]}$ where the $\varepsilon$-martensite possesses a close-packed hexagonal crystal structure. However, within a suitable composition range of $\mathrm{Mn}$ and $\mathrm{Al}$ solutes in ternary Fe-Mn-Al alloys, we found evidence of ferritic lath martensite herein. The formation mechanism of the ferritic lath martensite is different from that of traditional ferritic lath martensite in steel, however. In low-carbon steel, the ferritic lath martensite forms via quenching from high temperature, whereas slower cooling rates form ferrite and pearlite. The formation of the ferritic lath martensite in the Fe-Mn-Al alloy is not affected by the cooling rates, however, and is thus quite similar to maraging steel in the way the cooling rate does not play a role in the formation of the martensite. ${ }^{[15-21]}$ Here, we report that the austenite-ferrite martensitic transformation occurs in the Fe-16.7 Mn-3.4 Al alloy after cooling from high temperature.

\section{MATERIALS AND METHODS}

Ingots with the composition Fe-16.7 Mn-3.4 Al (wt pct) were prepared using an induction furnace, where electrolytic manganese, aluminum, and iron were melted together and cast into $3 \mathrm{~kg}$ ingots. The ingots were homogenized at $1473 \mathrm{~K}$ for $4 \mathrm{~h}$ under an argon atmosphere, hot forged into plates, and then annealed to assure composition uniformity. The alloy plates were cold rolled into plates $2 \mathrm{~mm}$ thick and cut into $10 \mathrm{~mm} \times$ $10 \mathrm{~mm}$ samples. These samples were heated at $1373 \mathrm{~K}$ for $1 \mathrm{~h}$ in a protective argon atmosphere, and were subsequently either air cooled, quenched, or furnace cooled to room temperature.

The samples for optical microscopy and scanning electron microscopy (SEM) were cut, polished using abrasive grinding papers, and etched using 5 pct Nital etchant. Transmission electron microscopy (TEM) specimens were ground into thin foils about $80 \mu \mathrm{m}$ thick using abrasive grinding papers, and were then punched into disks $3 \mathrm{~mm}$ in diameter and electro-polished using a twin jet polisher in a 90 pet $\mathrm{CH}_{3} \mathrm{OH}$ and 10 pet $\mathrm{HClO}_{4}$ solution at room temperature. The specimens were ion milled to further polish the thin areas of the TEM specimens. The specimens were examined in an FEI Tecnai G2 F-20 TEM operated at $200 \mathrm{kV}$.

\section{RESULTS AND DISCUSSION}

The optical micrograph (OM) in Figure 1(a) shows that the alloy grains contain irregular sub-grains within their boundaries. The secondary electron image obtained by SEM in Figure 1(b) also illustrates that the alloy matrix comprises irregular sub-grains that are quite similar to martensitic laths in low-carbon steel. $^{[16,17]}$ The crystal structures of the alloy were examined by XRD in Figure 1(c), which shows that the as-quenched Fe-Mn-Al alloy is composed primarily of BCC ferrite and a minor amount of FCC austenite. Thus, the as-quenched alloy possesses dual phases of ferrite and austenite, high-temperature prior grains, and with irregular martensitic sub-grains inside. The phase fractions could not be quantified using XRD because of the issues arising from the texture of the alloy after cold rolling and subsequent heat treatment. To clarify the distribution of the grains of the major ferrite and the minor austenite in the as-quenched Fe-Mn-Al alloy, we, therefore, performed a TEM study, shown in Figure 2.

Figure 2(a) shows the TEM bright-field (BF) image of the alloy sample in the as-quenched condition, and a corresponding selected area diffraction pattern (SADP) obtained from the martensitic sub-grain is shown in Figure 2(b). Several other SADPs along various zone axis directions of the martensitic laths are observed, and the crystal structure of the martensitic laths is confirmed as BCC ferrite $(\alpha)$. The zone axis direction of the SADP in Figure 2(b) is identified as ferrite [111]. We also examined several other regions located between the martensitic laths and found the existence of retained austenite grains within the matrix. Another BF image in Figure 2(c) shows retained austenite grains $(\gamma)$ as dark stripes distributed along the boundaries between martensitic laths. The SADP obtained from the retained austenite in Figure 2(d) shows that the zone axis direction is along the austenite [001]. The result from the TEM observation is consistent with that observed in XRD (Figure 1(c)), confirming that the major phase is ferrite and the minor phase is austenite. Thus, the microstructural study indicates that the as-quenched Fe-Mn-Al alloy is composed of ferrite in the form of ferritic lath martensite and retained austenite. In addition, we provide evidence for the occurrence of a martensitic transformation of the alloy when cooled from high temperature. Therefore, it is concluded that the irregular grains of the as-quenched alloy comprise dual phases primarily of BCC ferrite and a minor amount of FCC austenite, where the ferrite is in martensitic lath form and the austenite is retained austenite located between the martensitic laths. The grains of the dual phases both exhibit various irregular shapes. 

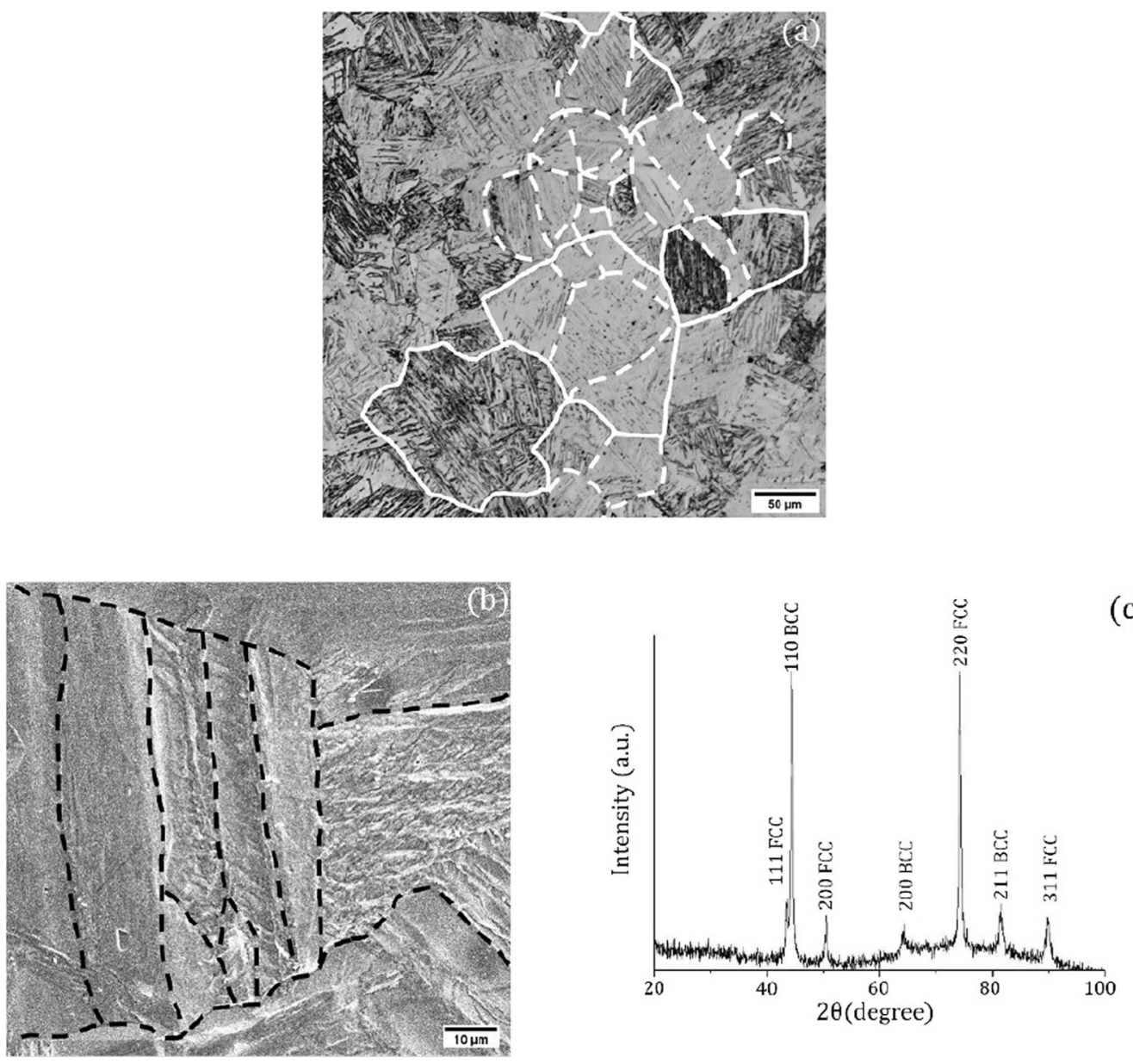

(c)

Fig. 1-Microstructural study of the Fe-Mn-Al alloy using (a) OM, (b) secondary electron SEM image, and (c) XRD after heating at $1373 \mathrm{~K}$ and quenching in room temperature water. Outlines of some of the grains (solid lines) and sub-grains (dashed lines) are marked in (a) and (b).

Furthermore, micro-twins are found to exist in the martensitic laths, as evidenced by the TEM BF image in Figure 2(e) showing the micro-twins $(t)$ in the martensitic laths. The SADPs obtained from the martensitic laths with micro-twins exhibit extra diffraction spots from a double diffraction. This implies that the martensitic lath contains single ferrite as well as ferrite twins. In addition, the contrast of the martensitic lath in the BF image of Figure 2(e) suggests the existence of at least two different crystal structures in the ferrite lath. Detailed analysis confirms that the martensitic lath consists of ferrite and its twins. The SADP in Figure 2(f) provides evidence for the existence of the ferrite twins, where the zone axes of the SADP are along the ferrite [101] direction (i.e., [1101 $]_{\alpha}$ ) and twin [011] direction (i.e., $[\underline{0} 1 \underline{1}]_{t}$, where the underline and subscript $t$ indicate the twin ferrite Miller indices). The diffraction spots connected by dashed white lines in Figure 2(f) indicate the ferrite matrix, while those connected by solid white lines indicate the ferrite twin. The twinning relationship between the ferrite twin and ferrite matrix is $[\underline{0} \overline{1} 1]_{t} / /$ $[101]_{\alpha}$ and $(121)_{t} / /(211)_{\alpha}$. The representative twin planes are the (121) planes of the twin and the (211) planes of the ferrite matrix. When studying the $\mathrm{BCC}$ twins by TEM, extra reflections occur on the SADPs owing to double diffraction. As shown on the SADP in Figure 2(f), the extra diffraction spots from the double diffraction occupy one third and two thirds of the distance between the (211) reflections of ferrite. ${ }^{[14]} \mathrm{A}$ dark-field (DF) image in Figure 2(g) gives further evidence for the existence of micro-twins in the ferritic lath martensite, where Figure 2(h) shows the corresponding BF image. There are four micro-twins located in the martensitic laths as shown in both Figures $2(\mathrm{~g})$ and (h). The ferritic lath martensite in low-carbon steel is full of dislocations and the formation of the ferritic lath martensite is assisted by the movement of dislocations ${ }^{[16-18]}$ However, in the ternary Fe-Mn-Al alloy, the martensitic laths also have a high density of dislocations and some micro-twins. Thus, the formation of ferritic lath martensite is primarily assisted by the movement of dislocations in the Fe-Mn-Al alloy. However, the formation of the ferrite micro-twins in the martensitic laths may also assist the martensitic transformation.

In addition to being present in the as-quenched Fe-Mn-Al alloy, ferritic lath martensite is also observed in the alloy after various cooling procedures from high temperature; namely, air cooling and furnace cooling. Figure 3 shows the microstructural study of the $\mathrm{Fe}-\mathrm{Mn}$-Al alloy heated to $1373 \mathrm{~K}$ with subsequent air 

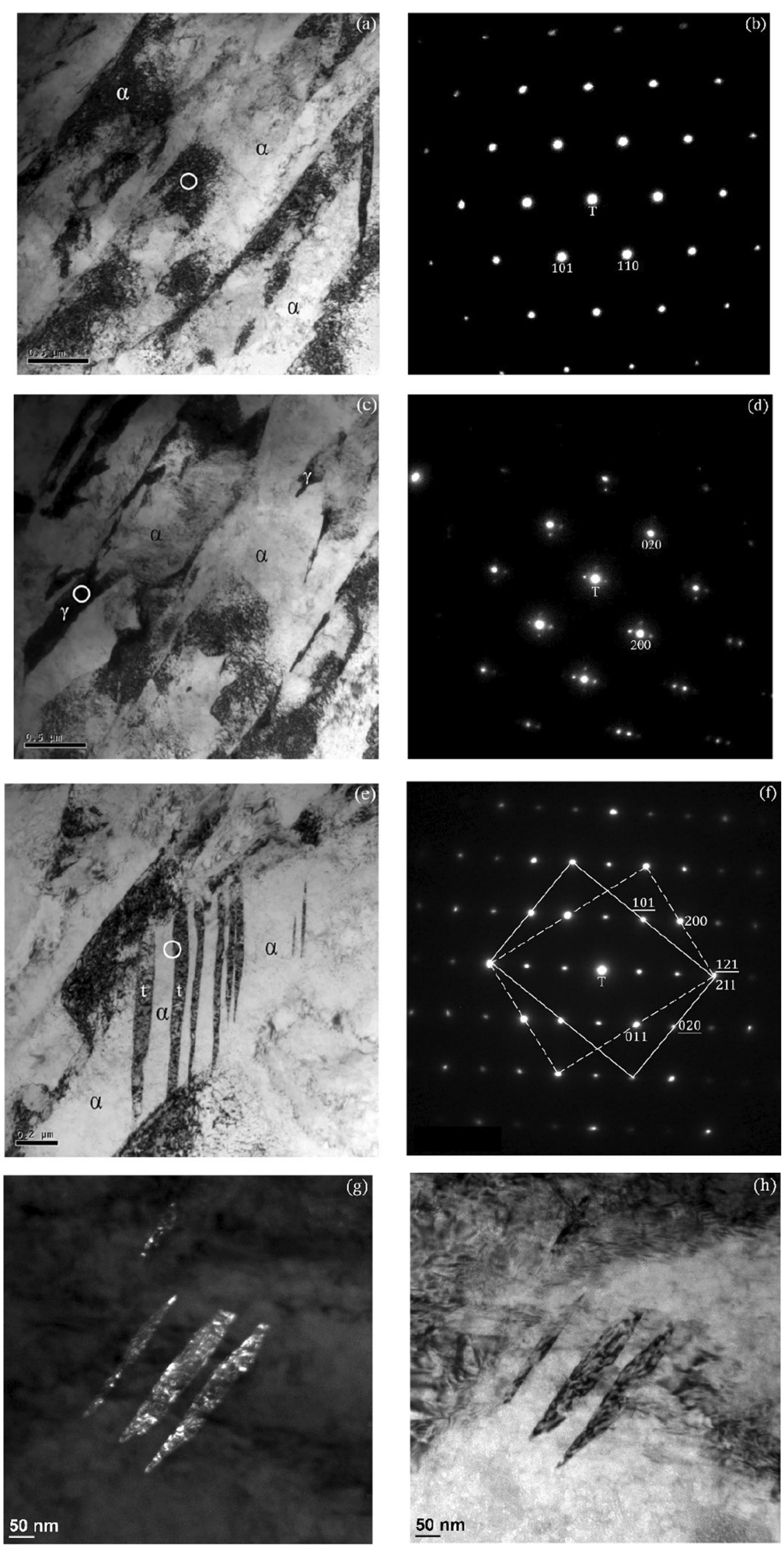
4Fig. 2-TEM micrographs of the alloy in the as-quenched condition: (a) BF image, (b) corresponding SADP from the [111] ferritic martensite (white circle in (a)); (c) BF image of retained austenite grains as dark stripes and $(d)$ corresponding SADP of [001] (white circle in (c)); (e) $\mathrm{BF}$ image of micro-twins in the ferritic martensite and $(f)$ corresponding twinning SADP along the $\left.\underline{0} \underline{1}_{t} / /[\overline{1} 01] 01\right]_{\alpha}$ zone axes (white circle in (e)); $(g)$ dark-field TEM image taken on the 111 ferrite twin reflection showing the existence of micro-twins and $(h)$ corresponding BF image. The underlined Miller indices indicate the ferrite twin, as distinguished from the ferrite matrix. The grains are marked as ferrite matrix $(\alpha)$, ferrite twin $(t)$, and austenite $(\gamma)$.

cooling at room temperature. Martensitic laths are observed in the matrix grains, as shown in Figure 3(a), where the morphology of the as-air-cooled alloy is similar to that of the as-quenched alloy in Figure 1(a). The constituent phases of the as-air-cooled alloy examined by XRD, shown in Figure 3(b), are found to be primarily ferrite and a minor amount of austenite. The crystal structure of the alloy after the air-cooling condition was also studied by TEM. The as-air-cooled alloy is full of martensitic laths, and Figure 3(c) shows a $\mathrm{BF}$ image of the martensitic laths and the corresponding SADP in Figure 3(d) obtained from the martensitic lath, where the zone axis of the SADP is along the ferrite [111]direction. Many dislocations can be observed in Figure 3(c), confirming that both as-quenched and as-air-cooled specimens possess many dislocations. However, it appears that the as-air-cooled specimen has more dislocations owing to the fact that the sample tilting angle is near the exact zone axis of the BCC [111] in Figure 3(c). Thus, the dislocations exhibit a darker contrast in the TEM BF image of Figure 3(c) (as-aircooled) than that in Figure 2(a) (as-quenched) and appears to have more dislocations. These results indicate that martensitic transformation also occurs in the Fe-Mn-Al alloy after air cooling from $1373 \mathrm{~K}$.

To further determine if the cooling procedure does not play a role in the formation of ferritic lath martensite in the Fe-Mn-Al alloy after cooling from high temperature, we heated the Fe-Mn-Al alloy to 1373 $\mathrm{K}$, maintained this temperature for $1 \mathrm{~h}$, and
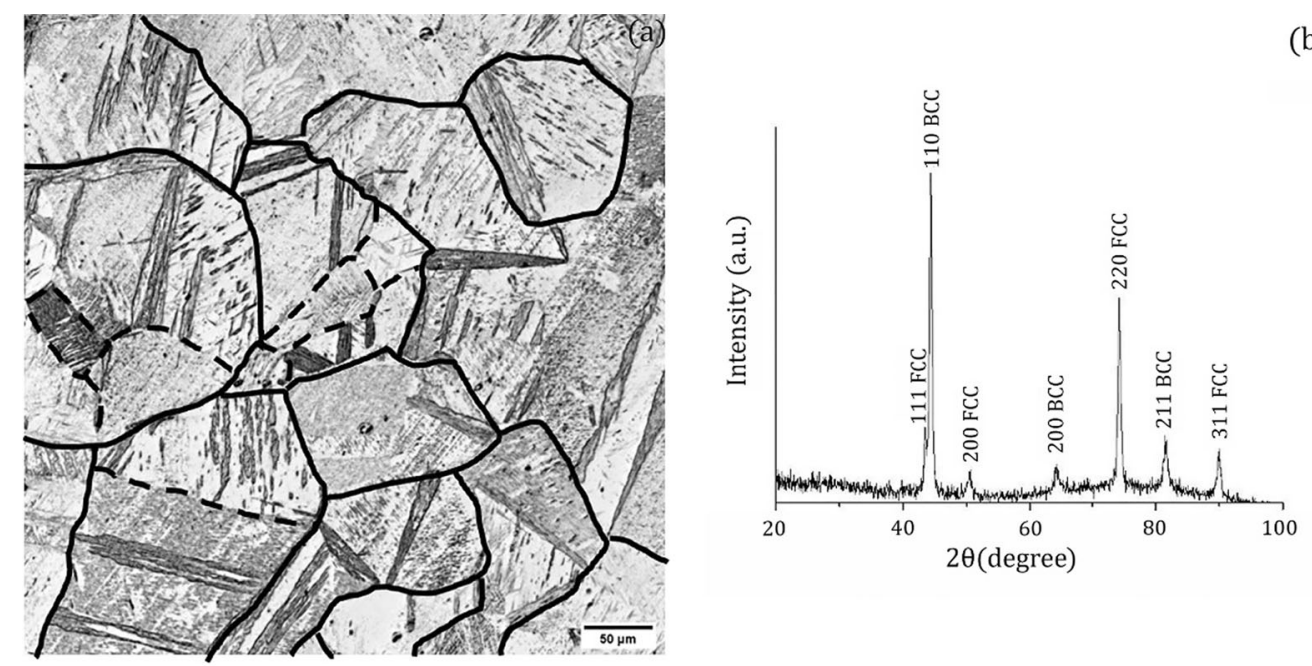

(b)
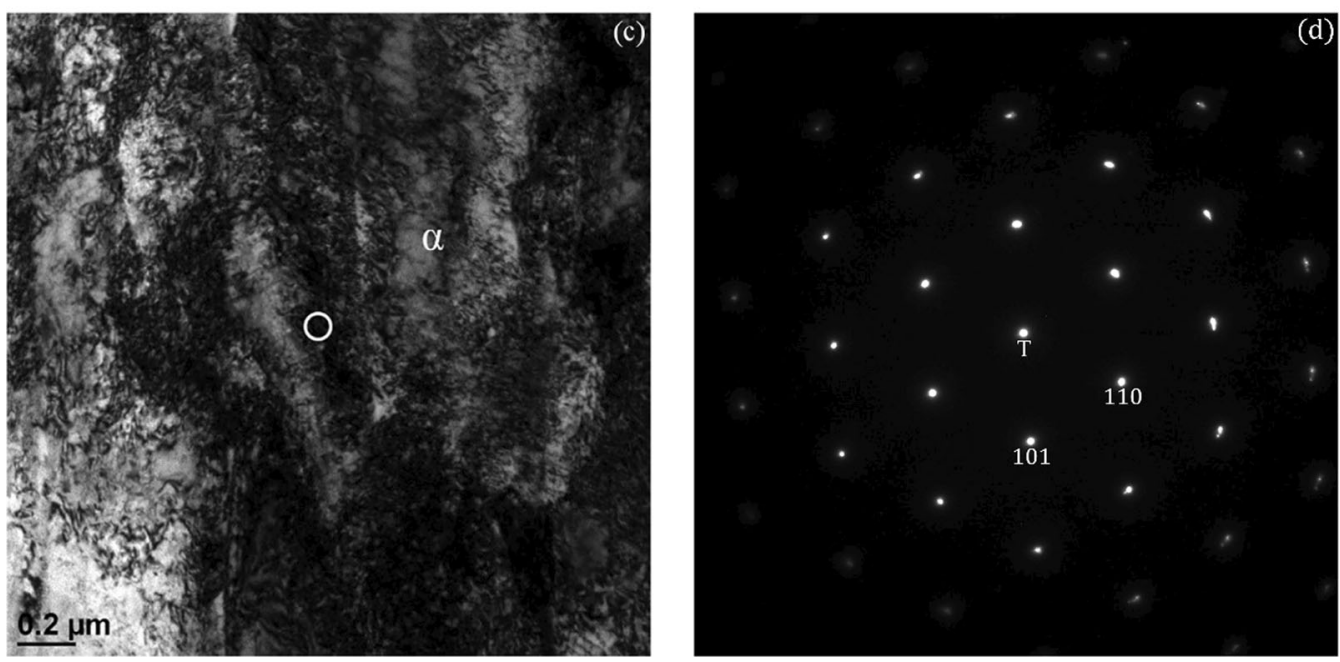

Fig. 3-Microstructural study of the Fe-Mn-Al alloy heated to $1373 \mathrm{~K}$ with subsequent air cooling to room temperature: $(a)$ OM, $(b)$ XRD, $(c)$ TEM BF image, and (d) SADP obtained from the ferritic lath martensite (white circle in (c)) from the [111] direction. Most grain boundaries (solid lines) and some sub-grains (dashed lines) are marked in (a). The grains are marked as ferrite matrix $(\alpha)$. 
subsequently furnace-cooled the alloy in Figure 4. The $\mathrm{OM}$ of the alloy microstructure shows that the alloy is full of martensitic laths in Figure 4(a). The XRD also reveals the as-furnace-cooled alloy comprises dual phases of primarily composed of ferrite and a minor amount of austenite in Figure 4(b). The microstructure of the as-furnace-cooled alloy was also examined using TEM, whereby the martensitic laths were found to occupy almost all matrix grains and only a few retained austenite grains remain. The evidence for the existence of the retained austenite is shown in Figures 4(c) and (d). The BF image in Figure 4(c) shows that primary ferritic laths are partially connected to retained austenite grains. Furthermore, the SADP in Figure 4(d) is obtained from the middle austenite grain shown in Figure 4(c), and the zone axis of the retained austenite is along the $[01 \overline{1}]$ direction.

It is confirmed that the microstructure of the as-furnace-cooled alloy comprises two phases of primarily lath ferrite and a minor amount of retained austenite. Therefore, we conclude that the formation of the ferritic lath martensite from the prior austenite grains of the $\mathrm{Fe}-\mathrm{Mn}-\mathrm{Al}$ alloy is not affected by the cooling rate. For the Fe-Mn-Al alloy after cooling from high temperature, slight strain energy fields associated with small temperature gradients during cooling can result in the martensitic transformation, and martensitic laths form within the prior austenite grains. Because the cooling rate does not play an important role in martensitic transformation, we posit that small temperature gradients are the driving force of the martensitic transformation. We heat-treated the steel with temperatures between $500{ }^{\circ} \mathrm{C}$ and $800{ }^{\circ} \mathrm{C}$ and found that small ferrite grains formed, though these results are not given in this work. We note that the ferrite and martensite are differentiable in steel and, although carbon is missing in the present alloy, the ferrite and ferritic martensite should exhibit differences. However, at this time we cannot distinguish between them with the instruments available to us. We have found these two phases almost identical via the study of the TEM SADP, and therefore no comments regarding their differentiation can be made in this study.

Herein, the FactSage 6.4 software was used to calculate the phase diagrams of the alloys using the FSstel database, ${ }^{[22]}$ where the alloy composition featured fixed 3.4 wt pet $\mathrm{Al}$ and varying Mn content from 0
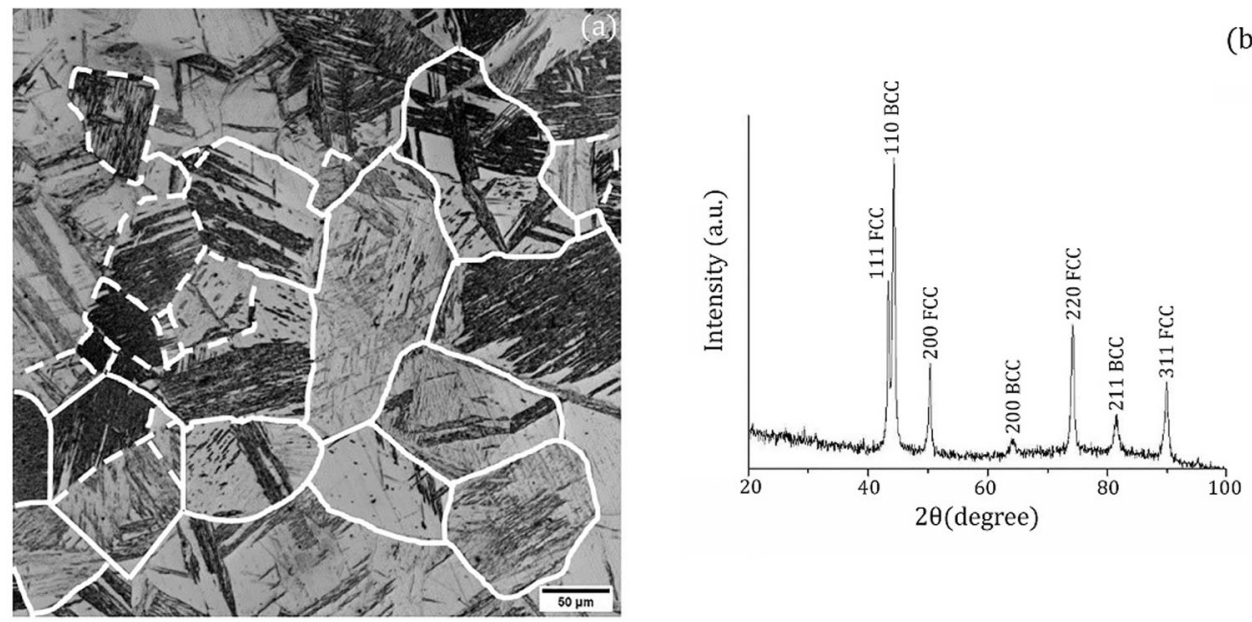

(b)
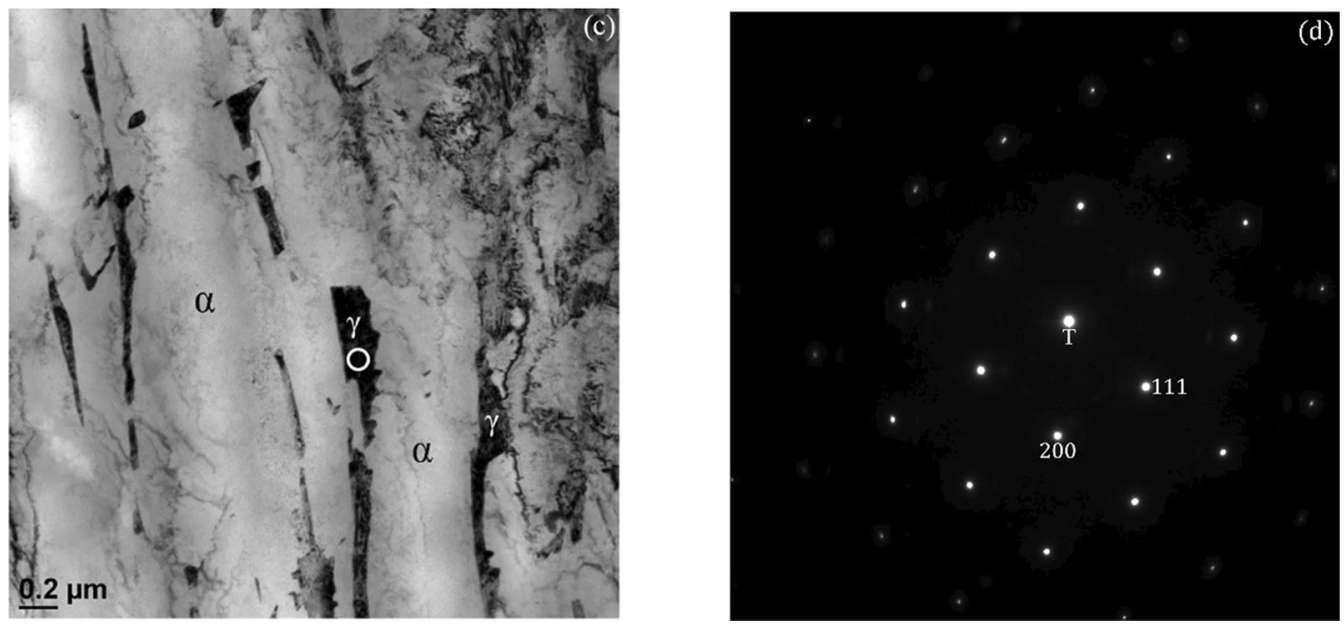

Fig. 4-Microstructural study of the Fe-Mn-Al alloy heated to and held at $1373 \mathrm{~K}$ for $1 \mathrm{~h}$ with subsequent furnace cooling to room temperature: $(a) \mathrm{OM},(b) \mathrm{XRD},(c)$ TEM BF image, and (d) SADP obtained from the retained austenite grain (white circle in (c)) from the [011̄] direction. Grains (solid lines) and laths (dashed lines) are marked in (a). The grains are marked as ferrite matrix $(\alpha)$ and austenite $(\gamma)$. 


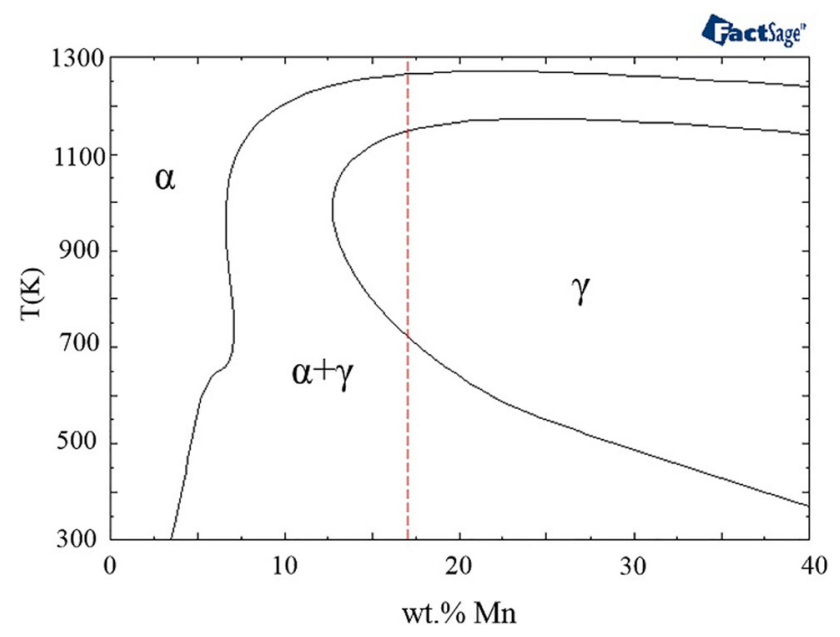

Fig. 5-Calculated partial phase diagram of the ternary $\mathrm{Fe}-\mathrm{Mn}-\mathrm{Al}$ alloy with a fixed $3.4 \mathrm{wt}$ pet $\mathrm{Al}$ composition and varying $\mathrm{Mn}$ content $\leq 40$ wt pet. The phases are marked as ferrite matrix $(\alpha)$ and austenite $(\gamma)$.

to $40 \mathrm{wt}$ pet in Figure 5. The high-temperature phases of the ternary Fe-Mn-Al alloys include austenite and ferrite. According to the phase diagram, the Fe-16.7 Mn-3.4 Al alloy (vertical dashed line in Figure 5) is completely austenite at temperatures ranging roughly from $725 \mathrm{~K}$ to $1125 \mathrm{~K}$. The phase diagram predicts that the Fe-16.7 Mn-3.4 Al alloy is single-phase ferrite at $1373 \mathrm{~K}$, though experimental observation suggests that the Fe-Mn-Al alloy should be single-phase austenite at this temperature. Thus, the region that is completely austenite is located at higher temperatures than predicted theoretically. Upon lowering the temperature from the single-phase austenite region, the constituent phases of the Fe-Mn-Al alloy change as follows: austenite $\rightarrow$ austenite + ferrite. Comparing the experimental observations of the Fe-16.7 Mn-3.4 Al alloy after cooling, we conclude that the occurrence of ferritic lath martensite along with the retained austenite is somehow consistent with the prediction of the theoretical phase diagram.

\section{CONCLUSIONS}

The austenite-ferrite martensitic transformation appears in the Fe-16.7 Mn-3.4 Al alloy when cooled from high temperature. We adopted various cooling procedures including furnace cooling, air cooling, and water quenching from $1373 \mathrm{~K}$, and observed the occurrence of the martensitic transformation in the alloy after all cooling procedures. This signifies that the martensitic transformation of the studied Fe-Mn-Al alloy that occurs after cooling from high temperature is not a function of the cooling rate. Therefore, a slight strain energy field coupled with small temperature gradients can result in the austenite-ferrite martensitic transformation of the alloy after cooling from high temperature. The ferritic martensitic grains are in the form of laths, where the martensitic laths formed in the prior austenite grains of the Fe-Mn-Al alloy are quite similar to those in low-carbon steel. In addition to the existence of dislocations, micro-twins are also found to exist in the ferritic lath martensite. The formation of ferritic lath martensite in the alloy is primarily assisted by the movement of the dislocations and may be assisted by the formation of the micro-twins. The twinning relationship between the ferrite twin (underlined indices and $t$ subscript) and ferrite matrix ( $\alpha$ subscript) is: $[\underline{0} \overline{1} 1]_{t} / /[\overline{1} 01]_{\alpha}$ and $(\underline{121})_{t} / /(211)_{\alpha}$. The twin planes of the BCC crystal are $\{112\}$. We believe this work presents compelling evidence that ferritic lath martensite similar to that in maraging steel has been found in the ternary Fe-Mn-Al alloys.

\section{ACKNOWLEDGMENTS}

The authors acknowledge financial support for this article from the Ministry of Science and Technology, Taiwan, under Grant Numbers: MOST 107-2923-E-011-003-MY3 and 109-2224-E-011-001. We thank Sara Maccagnano-Zacher, PhD, from Edanz Group (https://en-author-services.edanzgroup.com/ac) for editing a draft of this manuscript.

\section{OPEN ACCESS}

This article is licensed under a Creative Commons Attribution 4.0 International License, which permits use, sharing, adaptation, distribution and reproduction in any medium or format, as long as you give appropriate credit to the original author(s) and the source, provide a link to the Creative Commons licence, and indicate if changes were made. The images or other third party material in this article are included in the article's Creative Commons licence, unless indicated otherwise in a credit line to the material. If material is not included in the article's Creative Commons licence and your intended use is not permitted by statutory regulation or exceeds the permitted use, you will need to obtain permission directly from the copyright holder. To view a copy of this licence, visit http://creat ivecommons.org/licenses/by/4.0/.

\section{REFERENCES}

1. H. Kim, D.W. Suh, and N.J. Kim: Sci. Technol. Adv. Mater., 2013, vol. 14, pp. 014205-15.

2. S. Chen, R. Rana, A. Haldar, and R.K. Ray: Prog. Mater. Sci., 2017, vol. 89, pp. 345-91.

3. J.-E. Jin and Y.-K. Lee: Acta Mater., 2012, vol. 60, pp. 1680-88.

4. J. Han, S.H. Kang, S.J. Lee, M. Kawasaki, H.J. Lee, D. Ponge, D. Raabe, and Y.K. Lee: Nat. Commun., 2017, vol. 8, pp. 1-6.

5. W.C. Cheng and H.Y. Lin: Mater. Sci. Eng. A, 2002, vol. 323, pp. $462-66$

6. W.C. Cheng, H.Y. Lin, and C.F. Liu: Mater. Sci. Eng. A, 2002, vol. 335 , pp. $82-88$.

7. W.C. Cheng and C.K. Lai: Scripta Mater., 2006, vol. 55, pp. $783-86$.

8. W.B. Lee, F.R. Chen, S.K. Chen, G.B. Olson, and C.M. Wan: Acta Metall. Mater., 1995, vol. 43, pp. 21-30. 
9. H.Y. Chu, F.R. Chen, and T.B. Wu: Scripta Metall. Mater., 1995, vol. 33, pp. 1269-75.

10. W.C. Cheng, C.F. Liu, and Y.F. Lai: Scripta Mater., 2003, vol. 48, pp. 295-300.

11. W.C. Cheng, Y.C. Lin, and C.F. Liu: Mater. Sci. Eng. A, 2003, vol. 343 , pp. 28-35.

12. W.C. Cheng, Y.S. Lin, and K.F. Chen: Scripta Mater., 2014, vol. 81, pp. 36-39.

13. P.M. Kelly: Trans. Metall. Soc. AIME, 1965, vol. 233, p. 64.

14. C.M. Wayman and R. Bullough: Trans. Metall. Soc. AIME, 1966, vol. 236, p. 1711.

15. D.A. Porter, K.E. Easterling, and M.Y. Sherif: Phase Transformations in Metals and Alloys, 4th ed., CRC Press, New York, 2009, pp. 391-96.

16. T. Maki, K. Tsuzaki, and I. Tamura: Trans. Iron Steel Inst. Jpn., 1979, vol. 65 , pp. 515-24.
17. G. Krauss and A.R. Marder: Metall. Trans., 1971, vol. 2, pp. $2343-57$.

18. A.M. Hall and C.J. Slunder: NASA Technology Utilization Publications, Washington DC, 1968, pp. 27-28.

19. M.K. Banerjee: Compr. Mater. Finish., 2017, vol. 2, pp. 180-213.

20. A. Magnee, J.M. Drapier, J. Dumont, D. Goutsouradis, and L. Habraken: Cobalt-Containing High-Strength Steels, Centre d'Information du Cobalt: Brussels, 1974, pp. 23-42.

21. L. Remy: Metall. Trans. A, 1977, vol. 8, pp. 253-58.

22. R.A. Ricks, S.A. Parsons and P.R. Howell: in Proc. Int. Conf.: H.I. Aaronson et al.-editor, TMS-AIME, 1982, p. 831.

Publisher's Note Springer Nature remains neutral with regard to jurisdictional claims in published maps and institutional affiliations. 